DIW BERLIN

Discussion

Papers

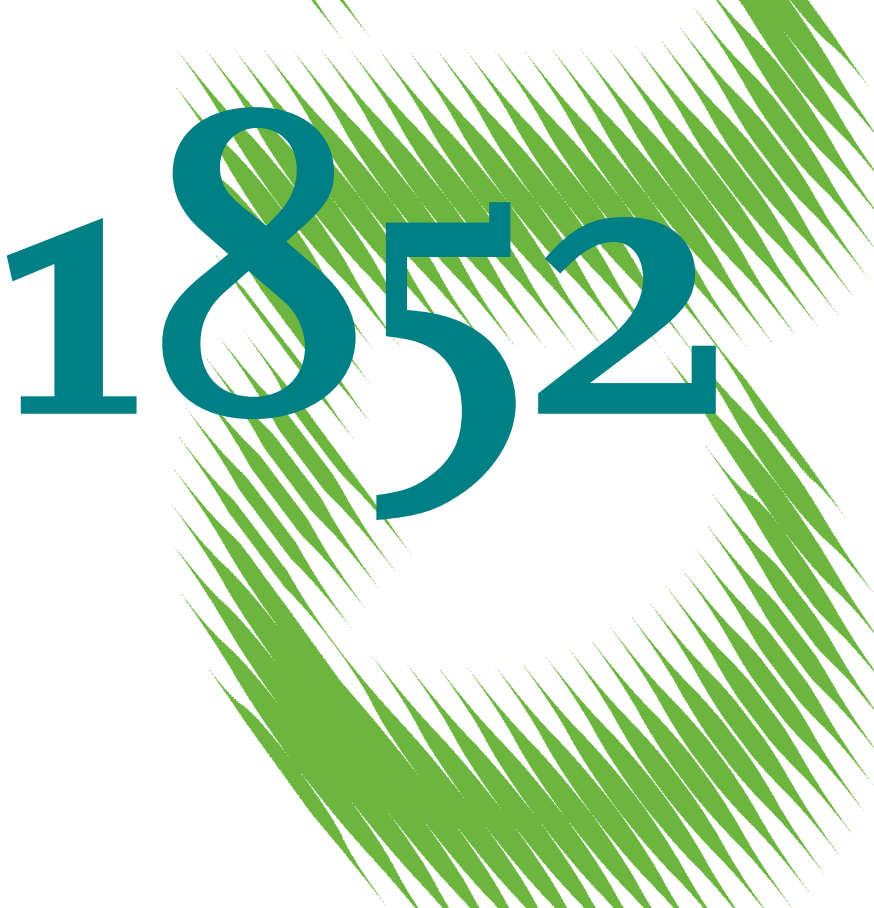

Inequality over the Business Cycle The Role of Distributive Shocks 
Opinions expressed in this paper are those of the author(s) and do not necessarily reflect views of the institute.

IMPRESSUM

(C) DIW Berlin, 2020

DIW Berlin

German Institute for Economic Research

Mohrenstr. 58

10117 Berlin

Tel. +49 (30) $89789-0$

Fax +49 (30) $89789-200$

http://www.diw.de

ISSN electronic edition 1619-4535

Papers can be downloaded free of charge from the DIW Berlin website:

http://www.diw.de/discussionpapers

Discussion Papers of DIW Berlin are indexed in RePEc and SSRN:

http://ideas.repec.org/s/diw/diwwpp.html

http://www.ssrn.com/link/DIW-Berlin-German-Inst-Econ-Res.html 


\title{
Inequality over the Business Cycle - The Role of Distributive Shocks
}

\author{
Marius Clemens (DIW Berlin, BERA), Ulrich Eydam (University of Potsdam), \\ Maik Heinemann (University of Potsdam) \\ February 13, 2020
}

This paper examines the dynamics of wealth and income inequality along the business cycle and assesses how they are related to fluctuations in the functional income distribution. In a panel estimation for OECD countries between 1970 and 2016 we find that on average income inequality - measured by the Gini coefficient - is countercyclical and also shows a significant association with the capital share. Up on a closer look, we find that a remarkable share of one third of all countries display a rather pro- or acyclical relationship. In order to understand the underlying cyclical dynamics of inequality we incorporate distributive shocks, modeled as exogenous changes in the capital share, into a real business cycle model, where agents are ex-ante heterogeneous with respect to wealth and ability. We show how to derive standard inequality measures within this framework, which allow us to analyze how productivity and distributive shocks affect both, the macroeconomic variables and the personal income and wealth distribution over the business cycle.

We find that whether wealth and income inequality in the model behaves countercyclical or not depends on two aspects. The intertemporal elasticity of substitution and the persistence of the shocks. We use Bayesian techniques in order to match GDP, capital share and consumption to quarterly U.S. data. The resulting parameter estimates point towards a non-monotonic relationship between productivity fluctuations and inequality. On impact, inequality increases in response to TFP shocks but declines in later periods. This pattern is consistent with the empirically observed relationship in the USA. Furthermore, we find that TFP shocks explain about 17 percent of the cyclical fluctuations in inequality in the USA.

JEL-Classification: D31, E25, E32

Keywords: Business Cycle, Income and Wealth Inequality, Distributive Shocks 


\section{Introduction}

In economics, the relationship between inequality and economic growth is controversially debated. Many studies concentrate on the long-term effects from inequality on growth or vice versa. Although surely a substantial amount of changes in the income and wealth distribution can be accounted for by structural changes, short term business cycle-related changes also have non-neglectable distributional effects: In recessions or booms income and wealth of specific-income groups will not grow symmetrically. For example, during a recession, households at the lower end of the income and wealth distributions are more negatively affected when becoming unemployed. This would make the income distribution rather countercyclical. In contrast, rich households who hold large parts of the capital stock face high capital income losses, which would rather lead to procyclical distributional dynamics. Therefore, it is a priori unclear how inequality behaves over the business cycle.

A large part of the current debate concentrates on trends for wealth and income inequality that are identified from the relevant data, see for example Alvaredo et al. (2017). Given the fact that the underlying statistics are still capable of development, in particular, we lack satisfactory statistics regarding the wealth distribution, and for both wealth as well as income inequality time series with a high periodicity even for the more recent past are missing, the business cycle perspective might be of some interest too. In order to assess the empirical evidence regarding the evolution of inequality and to discuss supposed structural causes, it is certainly helpful to know to what extent the recent trends in inequality can be attributed to business cycle dynamics or are truly the result of structural changes.

Recent studies use complex ex-ante heterogeneous-agent models (HAM, HANK) in order to analyze the interactions between inequality and the macroeconomy (Kaplan and Violante (2018), Ahn et al. (2017)). They focus on distributional effects of fiscal and monetary policies (Kaplan et al. (2018), Ragot and Grand (2017), Bayer and Luetticke (2018)) and also the causes and consequences of increasing income and wealth inequality in the U.S. (Kuhn et al. (2019), Bayer and Luetticke (2019)). There are also papers that try to reduce the complexity of heterogeneous agent models, i.e by using two agent, but still catch relevant part of the macro-inequality relationship (Iacoviello (2005), Galí et al. (2007), Challe et al. (2017), Debortoli and Galí (2017)). Clearly, analyzing the macro-inequality nexus within a full-fledged HANK model can and should not be replaced them. However, simplifying the macro-inequality relationship can provide stylized results which are testable with state-of-the art estimation methods (i.e. Bayesian estimation). Furthermore, the model can be used as approximation to get an impression to what extend inequality and the business cycle are related. Our paper contributes to this strand of literature by providing a simplified way to incorporate income and wealth inequality measures in a real business cycle model with TFP and distributive shocks.

Another topic, that has been discussed extensively in recent times are trends and fluctuations in the functional income distribution, i.e. changes in the capital and labor share. As documented by Growiec et al. (2018), functional income shares display a long run trend and fluctuate at business cycle frequencies. Ríos-Rull and Santaeulàlia-Llopis (2010), Mangin and Sedláček 
(2018) and Cantore et al. (2018) highlight that these fluctuations are linked to fluctuations in macroeconomic aggregates and have important implications for macroeconomic dynamics. As discussed by Atkinson (2009) it seems natural to expect that the functional income distribution is linked to the personal income distribution. Lansing (2015) incorporates persistent changes in the functional income distribution into a macro-model, in order to analyze the long-term development of the equity premium. Yet, how business cycle fluctuations in the functional income distribution are related to fluctuations in the personal income distribution has not been examined. In the present paper, we aim to fill this gap in the literature and provide an account of the cyclical properties of the personal and functional income distribution and their dynamic relationship.

In order to better understand short run inequality dynamics and the distributional consequences of oscillations in income shares, we proceed in two ways. First, we examine the cyclical correlation between GDP, the capital share and the Gini coefficient of the income distribution in a panel of OECD countries for the period between 1970 and 2017. The results of the panel regressions show that on average, the relationship between cyclical fluctuations in GDP and the Gini coefficient is statistically significant and countercyclical. Furthermore, the results also point towards a significant link between the functional and personal income distributions. However, a closer look at the contemporaneous correlations between the cyclical components reveals substantial heterogeneity across countries, i.e. roughly one third of countries in the sample, including the United States, show a rather procyclical or at least acyclical relationship between inequality and GDP. In a detailed examination of the cyclical relationships for the United States, we find that the Gini coefficient of the income distribution and the capital share are about one third as volatile as GDP. Furthermore, we observe a switching sign after around one year in the cross-correlations between GDP and the Gini coefficient.

Therefore, in a second step, we employ a real business cycle model with agents that differ with respect to their initial productivity and wealth endowments following the approach of Maliar et al. (2005). ${ }^{1}$ We use this framework and derive analytical expressions for several standard inequality measures which define the dynamics of the cross section in terms of aggregate variables. We put particular emphasize on the assumptions that are necessary for this derivation and discuss their implications regarding possible applications. In order to understand the role of cyclical variation in factor income shares and inspired by work of Young (2004), Ríos-Rull and Santaeulàlia-Llopis (2010) and Lansing (2015), we add distributive shocks to the model. Given the theoretical model, we show that the cyclicality of inequality depends crucially on the intertemporal elasticity of substitution and the shape of the stochastic process that induce aggregate dynamics.

Finally, to in order to test the theoretical predictions from our model and to match the theoretical considerations with the empirical findings, we use Bayesian methods and estimate the model, using data for the United States. ${ }^{2}$ In the light of the theoretical discussion, the estimated parameter values

\footnotetext{
${ }^{1}$ This approach builds on previous work in this respect by Chatterjee (1994) and Caselli and Ventura (2000), who examine inequality in a deterministic context. For a discussion of the model in a stochastic environment also see Maliar and Maliar (2001).

${ }^{2}$ The ability to estimate the model is one advantage of the approach presented here. In contrast to models with ex-post heterogeneity, which results from incomplete markets, as for example in Aiyagari (1994), the present model can be solved via perturbation and admits a compact state space representation that is easily suitable for estimation via
} 
suggest a procyclical relationship between inequality measures and GDP. This is also confirmed by the respective impulse responses, where we observe that inequality increases in response to TFP and distributive shocks. However, while the initial response of inequality measures to a TFP shock is positive, inequality starts to decline during the subsequent periods, i.e. the relationship turns countercyclical in the medium term. Thus, the estimated model is also able to replicate the negative sign of lagged cross-correlations between the cyclical components of inequality measures and GDP, observed for the United States. According to a variance decomposition of the empirical model, about $85 \%$ of the cyclical fluctuations in inequality measures in the United States result from distributive shocks. So overall, our results suggest that the observed differences in the cyclical relationship between inequality measures and GDP across countries can be traced back to differences in structural parameters and distinct causes of cyclical fluctuations. Furthermore, our analysis reveals the important role of distributive shocks for short run inequality dynamics.

The remainder of this paper is structured as follows. The second section presents the empirical findings for the group of OECD countries and the analysis of the cyclical properties of inequality measures, GDP and the capital share. The third section presents the theoretical model and the derivation of inequality measures. The fourth section discusses the models implications regarding the relationship between inequality and productivity shocks, as well as distributive shocks. Furthermore, it presents the results of matching the model to U.S. data and assesses the models ability to replicate empirical facts. The fifth section concludes.

\section{Inequality and the Business Cycle: Empirical facts}

\subsection{OECD Panel Comparison}

We start with a general assessment of the relationship between inequality and the business cycle. In the first step we estimate a panel fixed-effects model based on annual data between 1970 and 2016 in order to highlight the relationship between the state of the business cycle and inequality in OECD countries. Thereby we follow existing studies in explaining income inequality measured by the Gini coefficient of net disposable income. ${ }^{3}$ As main determinant of income inequality we consider GDP per capita, the squared GDP per capita and the degree of openness. Since we are interested in the relationship between inequality and the business cycle, we also consider the business cycle measured by the HP-filtered GDP series. ${ }^{4}$ Furthermore, to assess the relationship between the functional income distribution and the Gini coefficient, we include the cyclical component of the capital share. Inequality data were drawn from the UNU-WIDER Database, the data series for the macroeconomic variables stem from the Penn World Tables 9.0, as described in Feenstra et al. (2015).

\footnotetext{
Bayesian methods.

${ }^{3}$ See Barro (2000) for a comprehensive analysis. Since we concentrate on OECD countries, we do not control for colonies, political system and region specific dummies.

${ }^{4}$ We considered a smoothing parameter of 6.25. Business cycle data are introduced with a delay of one period as predetermined, to reduce the influence of reverse causality by assumption. We also conduct robustness analysis with different time periods, smoothing parameters and filtering methods (Bandpass filter, Hamilton Filter), but our results do not change quantitatively.
} 


\begin{tabular}{lll}
\hline \hline Gini coefficient & after redistr. & before redistr. \\
\hline GDP pc log & $-4.33^{* * *}$ & $-4.96^{* * *}$ \\
GDP pc squared & $0.09^{* * *}$ & $0.11^{* * *}$ \\
Business Cycle $_{t-1} \times 100$ & $-0.10^{*}$ & $-0.20^{* * *}$ \\
Capital share cycle $t-1 \times 100$ & $0.30^{* *}$ & $0.30^{* * *}$ \\
Openess $\times 100$ & -3.40 & 0.80 \\
\hline R-squared & 0.25 & 0.51 \\
Obs & 966 & 966 \\
Country FE & $\mathrm{Y}$ & $\mathrm{Y}$ \\
\hline \hline
\end{tabular}

* denotes $90 \%$-Significance-Level, ${ }^{* *}$ denotes $95 \%$-Significance-Level and ${ }^{* * *} \mathrm{de}-$ notes $97.5 \%$-Significance-Level. The Gini Coefficient after redistribution is the net Gini coefficient of disposable household income. Before redistribution it is the Gini coefficient of market income.

Table 1: The relationship between income inequality and the business cycle - OECD countries, $1970-2017$

Our baseline estimation, presented in table 1 , confirms results from previous studies: ${ }^{5} \mathrm{Ne}-$ glecting low and medium-income Non-OECD countries in the estimation cuts off the first part of the Kutznets curve, such that we observe a U-shaped relationship between income inequality and GDP per capita. Openness is positively correlated with income inequality but not statistically significant, mostly because openness in OECD countries does not vary much between countries. However, the business cycle of OECD countries, as measured by the cyclical component of GDP, is on average negatively and significantly correlated with income inequality. Although we estimate correlations, our results suggest that in a boom situation, income inequality may shrink, while recessions could lead to increases in income inequality. For cyclical variations in the functional income distribution, we detect a positive and statistically significant correlation. This indicates that increases in the capital share are on average associated with rising inequality. Finally, by comparing income inequality over the cycle before and after redistribution policy, we find that the relationship between business cycles and income inequality becomes less countercyclical after redistribution policies. This could be a sign for the effectiveness of automatic cyclical stabilizers, i.e. unemployment benefits or income tax in specific countries. ${ }^{6}$

While for the group of OECD countries income inequality is on average countercyclical, we can draw a different picture if we focus on country-specific correlations. Figure 1 highlights the heterogeneity across OECD countries. The graph sorts the OECD countries by sign and size of the contemporaneous correlation between income inequality and the business cycle. While around 50 percent of all countries exhibit a negative correlation, in some countries income inequality is acyclical (e.g. Austria) or even shows a procyclical pattern (e.g. Germany, Switzerland).

\footnotetext{
${ }^{5}$ See i.e. List and Gallet (1999) and Pothier and Puy (2014).

${ }^{6}$ Note that after redistribution, the significance level of the coefficient on the cyclical component of GDP decreases which could also indicate a decoupling of inequality and business cycle fluctuations through redistribution.
} 




Figure 1: Contemporaneous correlation between cyclical components of the income Gini and real GDP for OECD countries, annual averages between 1970-2017

\subsection{United States}

To corroborate further on this specific pattern, figure 2 shows the cyclical components of GDP, the capital share and the Gini coefficient of the income distribution for the United States. The cyclical relation can be summarized by four main characteristics: First, capital share moves rather procyclical in accordance with fluctuations in $\mathrm{GDP}^{7}$. Second, fluctuations of the Gini coefficient do not show such a clear pattern. Here we observe both, periods where the Gini coefficient moves in tandem with GDP and periods where inequality behaves rather countercyclical. For example, during the recession in the early 1980s, we observe a decline in output, while income inequality increased which suggests a countercyclical relationship. In contrast, over the expansion period, preceding the Great financial crisis, we observe increasing income inequality, which points towards a procyclical relationship. Third, the cyclicality of the functional income distribution measured by the capital share tend to lead movements of the income inequality. Fourth, we see that fluctuations in the capital share and Gini coefficient are small, compared to fluctuations in GDP.

\footnotetext{
${ }^{7}$ This observation is inline with the results of Growiec et al. (2018) who document countercyclical behavior of the US labor share.
} 


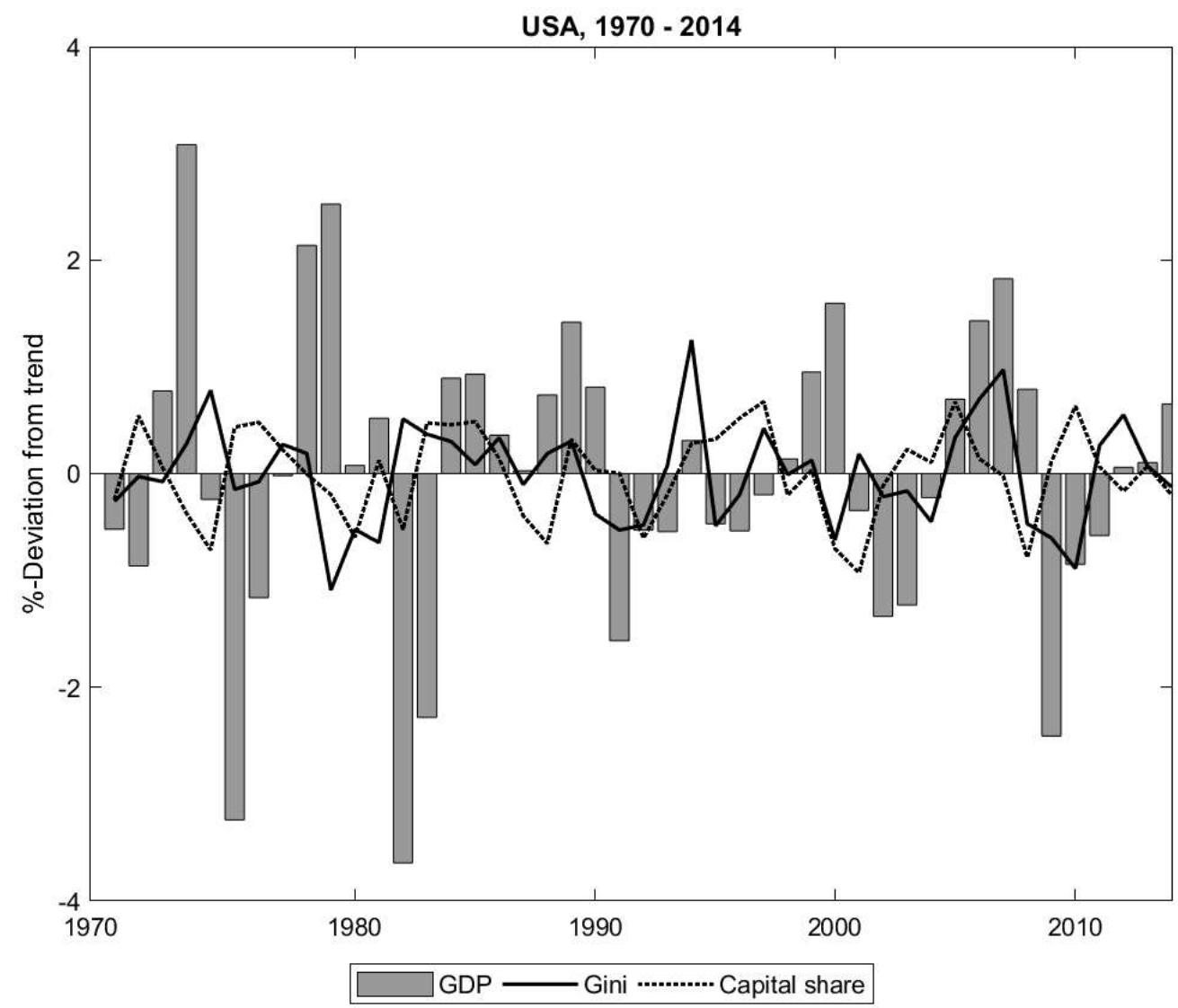

Figure 2: Cyclical components of real GDP, income Gini and capital share for the United States $1970-2016$.

This general pattern is also confirmed by the respective statistics presented in table 2 . The upper panel shows the standard deviation of the cyclical components for all three variables. Here we see that the variation in Gini coefficients and capital shares amounts to roughly one third of the variation in GDP, indicating that cyclical movements in inequality are less pronounced compared to GDP fluctuations. The lower panel shows the cross-correlations for the cyclical components of the Gini coefficient and GDP. We find a small positive contemporaneous correlation between GDP fluctuations and fluctuations in the Gini coefficients of the income distribution. This finding contrasts with the findings of Dimelis and Livada (1999), who document a countercyclical relationship between inequality measures and GDP for the US. This difference probably results from a different observational period. Furthermore, the cross-correlations also reveal that the dynamic relationship between fluctuations in output and inequality is characterized by sign switching. While the contemporaneous correlation indicates a non-significant positive association between GDP fluctuations and fluctuations in inequality, the relationship turns negative and statistically significant for the lead values of the Gini coefficient.

As discussed by Atkinson (2009), there is no clear cut relationship between the functional income distribution and the personal income distribution. How changes in the functional income distribution affect personal income inequality depends on the distribution of endowments. As 
shown in the regression analysis, cyclical movements in the capital share are on average positively associated with increases in the Gini coefficient of the income distribution for OECD countries. This can be rationalized if we interpret these cyclical fluctuations as a result of biased technological change, i.e. labor or capital augmenting technology shocks. Those shocks affect the functional income distribution and lead to changes in factor prices what eventually translates into changes in the personal income distribution. Thus, in order to understand fluctuations in the personal income distribution over the business cycle it seems necessary to take fluctuations in the functional income distribution into account.

\begin{tabular}{lcll}
\hline \hline & GDP $_{t}$ & Capital Share & Gini $_{t}$ \\
\hline Standard Deviation $\times 100$ & 1.40 & 0.40 & 0.40 \\
\hline Correlation with & & & \\
\hline Gini $_{t-2}$ & 0.04 & 0.00 & 0.23 \\
Gini $_{t-1}$ & 0.22 & 0.06 & 0.20 \\
Gini $_{t}$ & 0.09 & 0.08 & 1.00 \\
Gini $_{t+1}$ & -0.03 & 0.13 & \\
Gini $_{t+2}$ & $-0.34^{* *}$ & $0.21^{*}$ & \\
\hline \hline
\end{tabular}

${ }^{*}$ denotes $90 \%-,{ }^{* *} 95 \%-$, and ${ }^{* * *} 97.5 \%$-Significance-Level.

Standard deviation of cyclical components of real GDP, capital share and income Gini. Dynamic correlations of the cyclical components of real GDP and income Gini.

Table 2: Characteristics of the cyclical relation between GDP, functional and personal income distribution measures, U.S. 1970-2016

Overall, we interpret the empirical findings as evidence for business cycle related fluctuations in income inequality and as an indication of the crucial role of the capital share in shaping the dynamic pattern. However, because our empirical findings cannot be interpreted as causal we cannot rationalize the sign switch and the underlying dynamic pattern. Therefore, we augment a real business cycle model by income and wealth distributions which allows us to track the business cycle dynamics. The model also provides a structure that helps us to analyze the causal effects by identifying exogenous (business cycle and distributive) shocks. Furthermore, a pure data-based business cycle analysis of wealth inequality is very limited due to the lack of data availability, even at an annual frequency. With a structural model that tracks the observed dynamics of income inequality over the business cycle, we are able to simulate hypothetical business cycle effects on the income and wealth distribution.

\section{Model}

\subsection{Structure of the Model}

The basic structure of the model is equivalent to Maliar et al. (2005). The economy consists of a set of agents $I=[0,1]$. Agents are heterogeneous with respect to their accumulated wealth levels and their labor productivity but identical in all other respects. Wealth $z(i)_{t+1}$ of an agent $i$ at the end of any period $t$ consists of physical capital and holdings of Arrow securities. Since these Arrow 
securities are in zero net supply, $\int_{I} z(i)_{t+1} d i=k_{t+1}$ holds, where $k_{t+1}$ denotes average physical wealth. Labor productivity of agent $i \in I$ is denoted by $e(i)$.

The production side of the economy is essentially the same as in a canonical standard real business cycle model with stochastic shocks to technology. However, in addition to the usual technology shocks, distributive shocks — as in Lansing (2015) and Ríos-Rull and SantaeulàliaLlopis (2010) - are included. The final output $y_{t}$ is produced by the following function:

$$
y_{t}=\exp \left(\theta_{t}\right) k_{t}^{\alpha_{t}} h_{t}^{1-\alpha_{t}}
$$

where firms use physical capital $k_{t}$ and labor $h_{t}$. Here $\exp \left(\theta_{t}\right)$ represents the level of productivity with $\theta_{t}$ following an $\operatorname{AR}(1)$ process, i.e. $\theta_{t+1}=\rho_{\theta} \theta_{t}+\varepsilon_{\theta, t}$. The capital share $\alpha_{t}$ can be used as measure for the functional income distribution. ${ }^{8}$ In contrast to the canonical real business cycle model it is assumed to be stochastic with

$$
\alpha_{t}=\frac{a \exp \left(\zeta_{t}\right)}{1+a \exp \left(\zeta_{t}\right)}
$$

, where $\zeta_{t}$ represents a distributive shock that follows the $\operatorname{AR}(1)$ process $\zeta_{t+1}=\rho_{\zeta} \zeta_{t}+\varepsilon_{\zeta, t}$ and $a$ is a parameter that can be used to calibrate the functional income distribution. ${ }^{9}$

Each agent maximizes his expected lifetime utility, where preferences are assumed to be of the GHH type, i.e. the period utility function of agent $i$ is

$$
u(i)_{t}=\frac{\left(c(i)_{t}-B \frac{h(i)_{t}^{1+\gamma}}{1+\gamma}\right)^{1-\eta}}{1-\eta}, \quad \gamma, \eta>0,
$$

where $c_{t}(i)$ denotes the individual real consumption, $h_{t}(i)$ individual labour supply, $\eta, \gamma$ and $B$ are parameters measuring the intertemporal substitution elasticity, the inverse Frisch labor elasticity and the relative preference for leisure.

As these preferences are of the Gorman form, there exists a representative consumer and aggregate dynamics are independent of the wealth distribution. Define labor productivity of the representative agent by $e=\left(\int_{0}^{1} e(i)^{\frac{1+\gamma}{\gamma}} d i\right)^{\frac{\gamma}{1+\gamma}}$ and let $x_{t}=c_{t}-B \frac{h_{t}^{1+\gamma}}{1+\gamma}$. Aggregate dynamics are then fully determined by the following set of equations (and a transversality condition which is not

\footnotetext{
${ }^{8}$ See Ríos-Rull and Santaeulàlia-Llopis (2010).

${ }^{9}$ For reasons of clarity in the presentation of the theoretical model we ignore possible spillover effects between both types of productivity shocks, as they were emphasized by Ríos-Rull and Santaeulàlia-Llopis (2010). However, in the quantitative assessment of the model, we incorporate a bi-variate shock process to take these effects into account.
} 
displayed here):

$$
\begin{aligned}
x_{t}^{-\eta} & =\beta E_{t}\left[R_{t+1} x_{t+1}^{-\eta}\right] \\
\exp \left(\theta_{t}\right) k_{t}^{\alpha_{t}}\left(e h_{t}\right)^{1-\alpha_{t}} & =c_{t}+k_{t+1}-(1-\delta) k_{t} \\
h_{t} & =\left(\frac{w_{t} e}{B}\right)^{1 / \gamma} \\
x_{t} & =c_{t}-B \frac{h_{t}^{1+\gamma}}{1+\gamma} \\
R_{t} & =1-\delta+\alpha_{t} \exp \left(\theta_{t}\right) k_{t}^{\alpha_{t}-1}\left(e h_{t}\right)^{1-\alpha_{t}} \\
w_{t} & =\left(1-\alpha_{t}\right) \exp \left(\theta_{t}\right) k_{t}^{\alpha_{t}}\left(e h_{t}\right)^{-\alpha_{t}} \\
\theta_{t+1} & =\rho_{\theta} \theta_{t}+\varepsilon_{\theta, t} \\
\zeta_{t+1} & =\rho_{\zeta} \zeta_{t}+\varepsilon_{\zeta, t},
\end{aligned}
$$

The intertemporal Euler equation (2a), the budget constraint (2b), the optimal labor supply (2c) and the intratemporal utility (2d) determine the household behavior. The factor price equations for capital (2e) and labor (2f) determine firm behavior. The model dynamics are initiated by TFP $(2 \mathrm{~g})$ and distributive shocks ( $2 \mathrm{~h})$.

While some initial values $k_{0}, \theta_{0}$ as well as $\zeta_{0}$ are required to use these equations for the computation of simulated time paths of aggregate variables, it is well known that the stochastic properties of these aggregate variables do not depend on initial values. As will become clear below, this is not the case for variables that describe the evolution of the cross sectional distribution of these variables.

In order to describe the cross sectional distributions of some variables of interest, we now look at the individual decision rules which are for all $t$ the solution of the following problem:

$$
\max _{\left\{c(i)_{t}, h(i)_{t}, k(i)_{t+1}\right\}_{t=0}^{\infty}} E_{t} \sum_{s=0}^{\infty} \beta^{s} \frac{x(i)_{t+s}^{1-\eta}}{1-\eta}
$$

s.t.

$$
\begin{aligned}
R_{t} k(i)_{t}+e(i) w_{t} h(i)_{t}+m(i)_{t}\left(\theta_{t}, \zeta_{t}\right) & =c(i)_{t}+k(i)_{t+1}+\int_{\Theta, \mathscr{Z}} p_{t}(\theta, \zeta) m(i)_{t+1}(\theta, \zeta) d \theta d \zeta \\
x(i)_{t} & =c(i)_{t}-B \frac{h(i)_{t}^{1+\gamma}}{1+\gamma} \\
\theta_{t+1} & =\rho_{\theta} \theta_{t}+\varepsilon_{\theta, t} \\
\zeta_{t+1} & =\rho_{\zeta} \zeta_{t}+\varepsilon_{\zeta, t}
\end{aligned}
$$

Here $m(i)_{t+1}(\theta, \zeta)$ denotes agents $i$ 's purchases of Arrow securities that pay out one unit in period $t+1$ if $\theta_{t+1}=\theta$ and $\zeta_{t+1}=\zeta$ and $p(i)_{t}(\theta, \zeta)$ denotes the respective price of these Arrow securities. The gross interest rate $R_{t}$ and the real wage $w_{t}$ are quantities that depend on aggregate state variables, i.e. $R_{t}=R\left(k_{t}, \theta_{t}, \zeta_{t}\right)$ and $w_{t}=w\left(k_{t}, \theta_{t}, \zeta_{t}\right)$. Optimization is also subject to the initial 
wealth endowment $\kappa$ of agent $i$, which is given by:

$$
\kappa(i)=R_{0} k(i)_{0}+m(i)_{0}\left(\theta_{0}, \zeta_{0}\right)
$$

Individual optimization (i.e. the Euler equation and the transversality condition) then implies (see Maliar et al. (2005) for a proof) that for all $t$ the following equation holds:

$$
\begin{aligned}
c(i)_{t}-e(i) w_{t} h(i)_{t}+k(i)_{t+1} & \\
+\int_{\Theta, \mathscr{Z}} p_{t}(\theta, \zeta) m(i)_{t+1}(\theta, \zeta) d \theta d \zeta & =R_{t} k(i)_{t}+m(i)_{t}\left(\theta_{t}, \zeta_{t}\right) \\
& =E_{t}\left[\sum_{s=0}^{\infty} \beta^{s} \frac{x(i)_{t+s}^{-\eta}}{x(i)_{t}^{-\eta}}\left(c(i)_{t+s}-e(i) h(i)_{t+s} w_{t+s}\right)\right]
\end{aligned}
$$

With $z(i)_{t+1}=k(i)_{t+1}+\int_{\Theta, \mathscr{Z}} p_{t}(\theta, \zeta) m(i)_{t+1}(\theta, \zeta) d \theta d \zeta$ denoting the wealth level of agent $i$ at the end of period $t$, equation (5) can be rewritten as:

$$
\begin{aligned}
z(i)_{t+1} & =w_{t}-c(i)_{t}+E_{t}\left[\sum_{s=0}^{\infty} \beta^{s} \frac{x(i)_{t+s}^{-\eta}}{x(i)_{t}^{-\eta}}\left(c(i)_{t+s}-e(i) h(i)_{t+s} w_{t+s}\right)\right] \\
& =E_{t}\left[\sum_{s=1}^{\infty} \beta^{s} \frac{x(i)_{t+s}^{-\eta}}{x(i)_{t}^{-\eta}}\left(c(i)_{t+s}-e(i) h(i)_{t+s} w_{t+s}\right)\right]
\end{aligned}
$$

Using the first order condition for optimal labor supply and the fact that the Gorman form of preferences implies that $x(i)_{t}=\mu(i) x_{t}$ for all $t$, this equation can be rearranged to get:

$$
z(i)_{t+1}=\left(\mu(i)-\left(\frac{e(i)}{e}\right)^{\frac{1+\gamma}{\gamma}}\right) E_{t} \sum_{s=1}^{\infty} \beta^{s} \frac{x_{t+s}^{1-\eta}}{x_{t}^{-\eta}}+\left(\frac{e(i)}{e}\right)^{\frac{1+\gamma}{\gamma}} z_{t+1}
$$

Finally, let $\phi(i)=(e(i) / e)^{\frac{1+\gamma}{\gamma}}$ (notice, that $\left.\int_{0}^{1} \phi(i) d i=1\right)$ and define $U_{t}=E_{t} \sum_{s=0}^{\infty} \beta^{s} x_{t+s}^{1-\eta}$, where $U_{t}$ follows the recursive equation: ${ }^{10}$

$$
E_{t} U_{t+1}=\frac{1}{\beta}\left(U_{t}-x_{t}^{1-\eta}\right)
$$

We then get that the wealth share $a(i)_{t}=z(i)_{t} / k_{t}$ of agent $i$ evolves over time according to:

$$
a(i)_{t+1}=(\mu(i)-\phi(i)) \frac{x_{t}^{\eta} U_{t}-x_{t}}{k_{t+1}}+\phi(i)
$$

\subsection{Distributional Dynamics}

Besides the initial values for the state variables (i.e. $k_{0}, \theta_{0}$ and $\zeta_{0}$ ) the initial cross sectional distributions of wealth endowments as well as productivities have to be specified in order to describe the distributional dynamics implied by the model.

\footnotetext{
${ }^{10}$ Notice, that $U_{t}$ is proportional (up to the constant $1 /(1-\eta)$ ) to expected utility of the representative agent and that $U_{t}$ boils down to the constant $1 /(1-\beta)$ when $\eta=1$.
} 
In what follows, the distribution of initial wealth shares $\mathfrak{a}(i)=\kappa(i) /\left(R_{0} k_{0}\right)$ as well as the distribution of transformed productivities $\phi(i)$ are regarded as exogenous objects. With this, equation (5) evaluated at $t=0$ implies that the share $\mu(i)=x(i)_{t} / x_{t}$ of agent $i$ is given by:

$$
\mu(i)=[\mathfrak{a}(i)-\phi(i)] \frac{R_{0} k_{0}}{x_{0}^{\eta} U_{0}}+\phi(i)
$$

Equation (8) determines the time invariant share $\mu(i)$ in dependence on the initial conditions of the model. Since $x(i)_{t}$ has to be greater than zero for all $i$, this equation in fact formulates a restriction over these initial conditions that has to be met:

Assumption 1 The initial distributions $\mathfrak{a}(i)$ and $\phi(i)$ are such that for all $i \in I$ :

$$
[\mathfrak{a}(i)-\phi(i)] \frac{R_{0} k_{0}}{x_{0}^{\eta} U_{0}}+\phi(i)>0
$$

In what follows we will generally assume that (A.1) is satisfied. Using (8), equation (7) describing the evolution of the wealth distribution now becomes

$$
a(i)_{t+1}=[\mathfrak{a}(i)-\phi(i)] p_{0} q_{t}, \quad t=0,1,2, \ldots
$$

where

$$
p_{t}=\frac{R_{t} k_{t}}{x_{t}^{\eta} U_{t}}, \quad q_{t}=\frac{x_{t}^{\eta} U_{t}-x_{t}}{k_{t+1}} .
$$

where $p_{t}$ can be interpreted as capital value weighted in utility terms. The initial value of end of period wealth holdings $a(i)_{1}$ is completely determined by the exogenous initial cross sectional distributions of wealth holdings $\mathfrak{a}(i)$ and labor productivities $\phi(i)$ as well as the initial values of the aggregate state variables (which pin down the values of $R_{0}, k_{0}, x_{0}, U_{0}$ and $k_{1}$ ). Thus, the dynamic properties of the wealth distribution also depend on initial values of aggregate state variables.

Equation (9) describes the dynamic evolution of the wealth distribution and given this it is possible to describe all other relevant cross sectional distributions. First, note that the transformed productivities $\phi(i)=(e(i) / e)^{\frac{1+\gamma}{\gamma}}$, are by construction equivalent to the ratio of individual efficiency hours worked to average efficiency hours and thus equivalent to the - therefore time invariant ratio $\omega(i)=\frac{w_{t} e(i) h(i)_{t}}{w_{t} e h_{t}}$ of individual labor income to average labor income. ${ }^{11}$ The cross sectional distribution of factor incomes can be computed from the model if it is assumed that there is no trade of contingent claims in equilibrium. ${ }^{12}$ While this will leave the individual lifetime budget constraints and therefore the allocation unchanged, it implies via (4) that $\mathfrak{a}(i)=a(i)_{0}$ and that the share $y(i)_{t}$ of agent $i$ in total factor income in period $t$ is given by:

$$
y(i)_{t}=\alpha_{t} a(i)_{t}+\left(1-\alpha_{t}\right) \phi(i)
$$

\footnotetext{
${ }^{11}$ Because $h(i)_{t}=\left(w_{t} e(i) / B\right)^{1 / \gamma}$ and $h_{t}=\left(w_{t} e / B\right)^{1 / \gamma}$, we have $\left(e(i) h(i)_{t}\right) /\left(e h_{t}\right)=(e(i) / e)^{(1+\gamma) / \gamma}=\phi(i)$.

${ }^{12} \mathrm{See}$ on this Maliar et al. (2005), who make the point that the lifetime budget constraints of the agents remain unchanged if there is no trade of contingent claims. However, if one wants to model an economy where some agents are initially indebted, this requires $k(i)_{0}<0$ such that $k(i)_{t}$ cannot be interpreted as an agent's holding of physical capital. In this case $k(i)_{t}$ represents individual net worth which aggregates to the aggregate capital stock $k_{t}$ as the sum of all debt has to be zero.
} 
Under the harmless assumption that $\mathfrak{a}(i)$ and $\phi(i)$ are both continuous on $I$, it is always possible to compute from equations (9) and (10) at least variances and covariances in a straightforward way in order to describe the dynamics of the cross sectional distributions of wealth and income. So for instance, the coefficient of variation $\sigma_{a, t}$ of $a(i)_{t}$ evolves according to:

$$
\sigma_{a, t+1}=\sqrt{\left(p_{0} q_{t}\right)^{2} \sigma_{\mathfrak{a}}^{2}+\left(1-p_{0} q_{t}\right)^{2} \sigma_{\phi}^{2}+2 p_{0} q_{t}\left(1-p_{0} q_{t}\right) \sigma_{\mathfrak{a}, \phi}^{2}}
$$

where $\sigma_{\mathfrak{a}}^{2}$ and $\sigma_{\phi}^{2}$ denote the cross sectional variances of $\mathfrak{a}$ and $\phi$, respectively and $\sigma_{\mathfrak{a}, \phi}^{2}$ denotes the cross sectional covariance between $\mathfrak{a}$ and $\phi$.

Of course, a more convenient way to characterize the distributional implications of the model would be to consider usual inequality measures like Gini coefficients. Below we will present equations that describe the approximated (i.e. linearized) dynamics of Gini coefficients. ${ }^{13}$ First, however, we will look at a special case that allows for a straightforward computation of Gini coefficients from the cross sectional distributions generated by the model. This case arises when $\mathfrak{a}(i)$ and $\phi(i)$ satisfy some preconditions that are summarized below:

Assumption 2 The initial distributions $\mathfrak{a}(i)$ and $\phi(i)$ are such that for all $i \in I=[0,1]$ :

(i) $\phi(i)$ is integrable and monotone increasing,

(ii) $\mathfrak{a}(i)$ is integrable and monotone increasing,

(iii) $\mathfrak{a}(i)-\phi(i)$ is integrable and monotone increasing.

Conditions (i) and (ii) imply that the Gini coefficients of the initial wealth and productivity distributions can be constructed simply by integration of $\phi(i)$ and $\mathfrak{a}(i)$. So, for instance, the Gini coefficient of the initial wealth distribution is given by $G_{\mathfrak{a}}=1-2 \int_{0}^{i} \int_{0}^{j} \mathfrak{a}(i) \operatorname{didj} .{ }^{14}$ As equation (9) reveals, condition (iii) then ensures that $a(i)_{t+1}$ is for all $t \geq 0$ integrable and monotone increasing on $I$ such that the Gini coefficient $G_{a, t+1}$ of the wealth distribution at the end of period $t$ can be constructed also simply by integration of $a(i)_{t+1}$. Finally this implies that $y(i)_{t}$ is also integrable and monotone increasing such that the Gini coefficient of the income distribution $G_{y, t}$ results by integrating $y(i)_{t}$. From (9) and (10) we therefore get:

$$
\begin{aligned}
G_{a, t+1} & =p_{0} q_{t} G_{\mathfrak{a}}+\left(1-p_{0} q_{t}\right) G_{\phi}, \\
G_{y, t} & =\alpha_{t} p_{0} q_{t-1} G_{\mathfrak{a}}+\left(1-\alpha_{t} p_{0} q_{t-1}\right) G_{\phi}
\end{aligned}
$$

with $p_{t}$ and $q_{t}$ as defined in (9) and with $G_{\mathfrak{a}}$ and $G_{\phi}$ denoting the exogenously given Gini coefficients of the endowment distributions. Notice that $p_{0}$ and the dynamics of $q_{t}$ are completely determined by the model parameters and the initial values of the aggregate state variables. Thus, together with $G_{\mathfrak{a}}$ and $G_{\phi}$ this then determines the dynamics of wealth and income inequality.

\footnotetext{
${ }^{13}$ In Appendix B we show how to derive a linearized representation of the coefficient of variation. In Appendix $\mathrm{C}$ we present a linearized version of a generalized entropy index. However, note that the cyclical variations of all these inequality measures are related through $q_{t}$ and are proportional to each other.

${ }^{14}$ Note that the Lorenz curve of the initial wealth distribution $L_{\mathfrak{a}}(j)$ is given by $L_{\mathfrak{a}}(j)=\int_{0}^{j} \mathfrak{a}(i) d i$.
} 
A special feature of the distributional dynamics described by equations (11) as well as (12a) and (12b) is that the cross sectional dynamics still depend on the initial value $p_{0}$. However, we will get rid of this initial value when we analyze the linearized dynamics of the inequality measures in the neighborhood of the steady state of the model. The resulting linearized counterparts of (12a) and (12b) are given by:

$$
\begin{aligned}
\hat{G}_{a, t+1} & =\hat{q}_{t}\left(1-\frac{G_{\phi}}{G_{a}}\right), \\
\hat{G}_{y, t} & =\left[\hat{q}_{t-1}+\hat{\alpha}_{t}\right]\left(1-\frac{G_{\phi}}{G_{y}}\right),
\end{aligned}
$$

where - as usual - the hat indicates that a variable represents a relative deviation from the respective steady state. ${ }^{15}$ In equations (13a) and (13b) $G_{\phi}$ is the exogenous inequality measure for labor income and all other variables without a time index represent respective steady state values.The steady state values of inequality measures for wealth and income itself are related through the following equation:

$$
G_{y}=\alpha G_{a}+(1-\alpha) G_{\phi}
$$

To summarize, the complete set of linearized equations describing aggregate as well as distributional dynamics is given by the linearized equations $(2 a)-(2 h)$ from above as well as the linearizations of (6) and the equation that defines $q_{t}$ :

$$
\begin{aligned}
E_{t} \hat{U}_{t+1} & =\frac{1}{\beta} \hat{U}_{t}+(1-\eta) \frac{1-\beta}{\beta} E_{t} \hat{x}_{t+1} \\
\hat{q}_{t} & =\frac{\eta+\beta-1}{\beta} \hat{x}_{t}+\frac{1}{\beta} \hat{U}_{t}-\hat{k}_{t+1}
\end{aligned}
$$

Thus, augmenting an otherwise conventional stochastic macroeconomic model with the just derived equations enables us to describe and simulate the distributional implications of exogenous shocks in that model. Moreover, equation (13a) and (13b), allow to derive some first conclusions regarding the business cycle properties of wealth and income inequality.

Concerning this, let us first look at the volatility of income and wealth inequality. Equations (13a) and (13b) reveal that this volatility depends on the one hand on the volatility of the aggregate variables $q_{t}$ and $\alpha_{t}$ and on the other hand on the cross sectional distribution of the stochastic steady state as determined by $G_{a}$ and $G_{\phi}$. There are two special cases where there is no volatility in inequality at all such that the wealth and income distributions remain unchanged over time. The first one is the case where $q_{t}$ as well as $\alpha_{t}$ are constant over time. While $\alpha_{t}$ is constant whenever there are no distributional shocks, $q_{t}$ stays constant only for certain parameterizations $(\eta=1)$ of the model (we will come back to this in the next section). The second case is the one where $\mathfrak{a}(i)=\phi(i)$ for all $i \in I$ (cf. equations (9) and (10)). In this case we have $G_{a}=G_{\phi}$, such that wealth and income inequality stay constant over time. Besides this, (13a) and (13b) allow for the conclusion that the volatility of wealth and income inequality will be larger, the larger the differences between

\footnotetext{
${ }^{15}$ We should note that the equations for Gini coefficients (13a) and (13b) are in fact exact representations of the true dynamics as long as the conditions of Assumption 2 are satisfied.
} 
wealth, labor income and total income distributions are. Another relevant business cycle feature is the cyclical behavior of wealth and income inequality. Regarding this, assume first that there are no distributive shocks (i.e. $\alpha_{t}=0$ ) and that the model is calibrated in a more or less plausible way such that $G_{a}>G_{\phi}$. In this case wealth inequality moves in the same direction as $q_{t}$, i.e. wealth inequality behaves procyclical whenever $q_{t}$ does so (and we will show later that a plausible calibration of the model implies that $q_{t}$ is in fact proyclical).

\section{Quantitative Analysis}

\subsection{Shocks and Inequality}

In order to assess the consequences of exogenous technology shocks for wealth inequality, it is useful to neglect any distributive shocks and to look at the dynamics of wealth inequality in a deterministic model first. Chatterjee (1994) and Caselli and Ventura (2000) performed such analyses and the latter paper shows that with $\eta=1$ and Cobb-Douglas technology the transition towards the deterministic steady state from below (above) goes along with declining (rising) wealth inequality. While this suggests that a positive technology shock in an equivalent stochastic model should go along with a decline in wealth inequality, we will see that this is not necessarily true as the serial correlation of the technology shocks also matters for the response of wealth inequality.

To see this, look at the ratios $\frac{x_{t}}{k_{t+1}} \frac{k_{t}}{x_{t-1}}$ that govern the dynamics of wealth inequality in the case the elasticity of intertemporal substitution is $\eta=1$ (cf. eqn. (7)). ${ }^{16}$ Assume that in period $t$ the economy is hit by a purely transitory and positive technology shock. Starting from $x_{t-1}=x^{*}$ and $k_{t}=k^{*}$, both $x_{t}$ as well as $k_{t+1}$ will increase, with the increase in $x_{t}$ being smaller than the increase in $k_{t+1}$. As a consequence, $x_{t} / k_{t+1}<x^{*} / k^{*}$ and wealth inequality will decline. If, however, the productivity shocks display a high enough degree of serial correlation, the increase in $x_{t}$ might well be larger than the increase in $k_{t+1}$, such that wealth inequality rises in response to a positive technology shock. This results because an anticipated long lasting future increase in TFP requires not that much investment.

\section{TFP shocks}

Figure 3 shows typical impulse responses of wealth inequality to a positive technology shock for different values of some of the model's parameters. ${ }^{17}$ The upper panel shows impulse responses for the case of serially uncorrelated shocks, the lower panel shows the responses for serially correlated shocks. As can be seen, whether or not wealth inequality increases in response to a positive technology shock - and thus behaves procyclical — depends on the intertemporal elasticity of substitution $1 / \eta$ and the persistence of productivity shocks $\rho_{\theta}$. In case shocks are not persistent, a negative response results for low enough values of $\eta<1$ or, conversely, a positive response now requires a large enough value of $\eta>1$. For plausible values of $\eta \approx 2$ and $\rho_{\theta} \approx 0.95$ wealth inequality rises on impact and then converges back to its steady state level. From the business cycle

\footnotetext{
${ }^{16} \eta=1$ implies $\frac{x_{t}^{\eta} U_{t}-x_{t}}{k_{t+1}}=\frac{\beta}{1-\beta} \frac{x_{t}}{k_{t+1}}$.

${ }^{17}$ The underlying model is calibrated - with respect to quarterly data - with $\beta=0.988, \delta=0.025, \alpha=0.38$. We set $G_{y}$ to 0.43 and $G_{a}$ is set to 0.8 . We plot the impulse responses only for wealth inequality, because the reactions of the wealth and income distribution are identical in case of TFP shocks.
} 

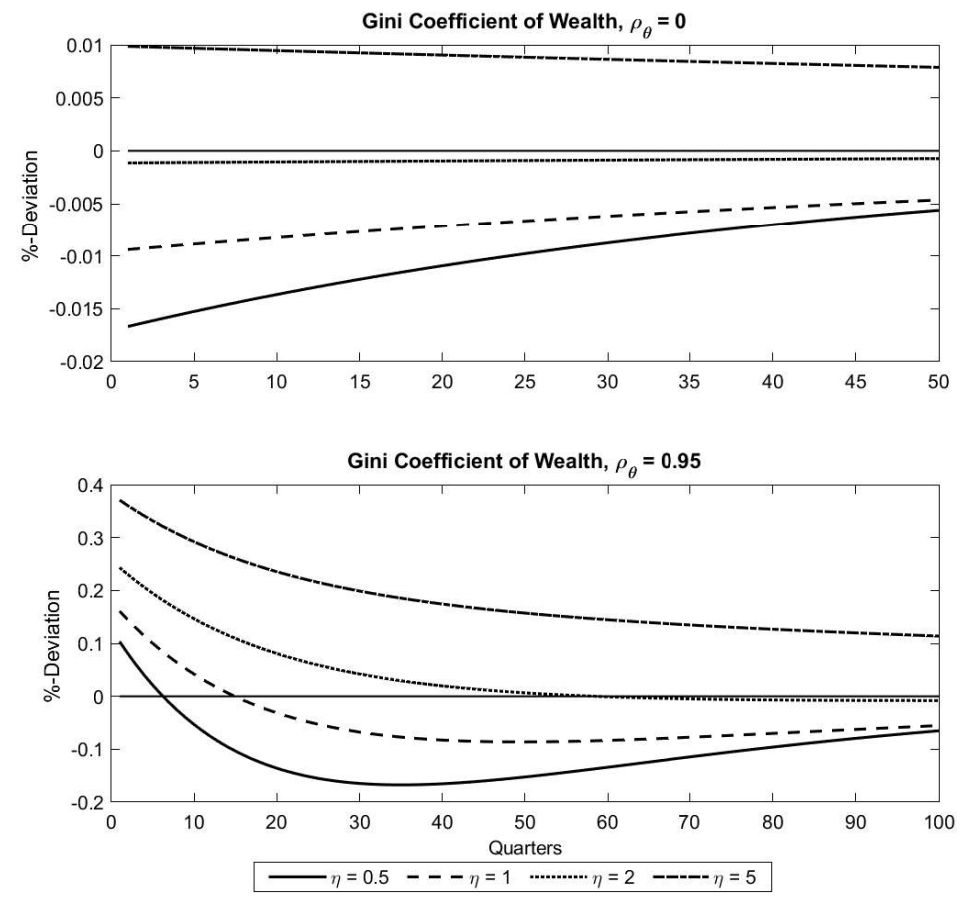

Figure 3: Impulse responses of wealth inequality to a positive technology shock at different values of $\eta$. Without persistent shocks $\left(\rho_{\theta}=0\right)$ in the upper panel, with persistent TFP shocks $\left(\rho_{\theta}=0.95\right)$ in the lower panel. The other parameters are set as follows: $\beta=0.98$, $\delta=0.025, \alpha=0.38$.

perspective this implies that wealth inequality behaves procyclical. Moreover, for low values of $\eta$ the adjustment of wealth inequality is non monotonic, i.e. during the transition, wealth inequality falls below its steady state level and converges to this level from below. ${ }^{18}$

In summary if technology shocks are the main drivers of business cycle fluctuations, procyclical behavior of wealth inequality results whenever the intertemporal elasticity of substitution $1 / \eta$ is low enough and/or the autocorrelation of the technology shocks is high enough. Intuitively, the importance of these parameters for inequality dynamics is straight forward. A high value of $\eta$ is associated with a strong preference for consumption smoothing. Thus, at higher values of $\eta$, households will be inclined to accumulate more capital in response to a productivity shock, in order to smooth out their consumption. Since households at the top of the wealth distribution have a higher capital income, they need to accumulate relatively more capital compared to poorer households, which eventually results in increasing wealth and income inequality. A similar reasoning applies to the persistence of shocks. In case of an uncorrelated one time increase in productivity, households will also smooth consumption but not as much as in the case of correlated shocks. Therefore, in this case we observe increasing wealth inequality only for high values of $\eta$. When shocks are serially correlated, the consumption smoothing motive dominates and inequality increases in response to productivity shocks.

\footnotetext{
${ }^{18}$ This non monotonic adjustment for low values of $\eta$ implies that it matters whether or not filtered output is used in order to compute cross correlations. So for example the HP filter will allocate more of the low frequency fluctuations to the trend component and will thus produce different cross correlations than unfiltered output.
} 


\section{Distributive shocks}

Next, we turn to distributive shocks. Again, we find that the response of inequality measures will crucially depend on the values of $\eta$ and $\rho_{\xi}$. Consider again the case of $\eta=1$ : If the economy is hit by a purely transitory distributive shock, the capital share increases and both, $x_{t}$ and $k_{t+1}$ will increase, where again, the increase in $x_{t}$ is smaller than the increase in $k_{t+1}$ and thus we see a decline in the Gini coefficient of the wealth distribution. However, as we can see from equation (13a) and (13b) in the case of distributive shocks, the Gini coefficients of the wealth and income distribution must not necessarily move into the same direction. While distributive shocks have only an indirect impact on the Gini coefficient of the wealth distribution through the effects on $\frac{x_{t}}{k_{t+1}}$, they exert an additional direct effect on the Gini coefficient of the income distribution. Thus, if the increase in $\alpha_{t}$ is large enough, it dominates the indirect effect and we see an increase in the Gini coefficient of the income distribution.


Figure 4: Impulse responses of wealth and income inequality to a positive distributive shock at different values of $\eta$ and $\rho_{\zeta}$. The left panels show the responses to uncorrelated shocks, the right panels show the responses to correlated shocks. The other parameters are set as follows: $\beta=0.98, \delta=0.025, \alpha=0.38$.

Figure 4 shows the reaction of the Gini coefficient of the wealth distribution (upper panels) and the Gini coefficient of the income distribution (lower panels) to uncorrelated (left panels) and correlated (right panels) distributive shock for different values of $\eta$. As can be seen, for uncorrelated shocks and $\eta=1$, the above reasoning applies and we see a decline in the Gini coefficient of 
the wealth distribution accompanied by a rise in the Gini coefficient of the income distribution. This pattern changes when either $\eta$ increases or the correlation of distributive shocks is taken into account. For $\eta>2$ both Gini coefficients show procyclical behavior in the case of uncorrelated shocks.

\subsection{Matching to U.S. data}

Next, in order to find an empirically plausible specification, we use Bayesian methods to match a subset of the model parameters to U.S. data. In a second step, we then compare the simulated Gini path with the historical data series. To this end, we focus mostly on the stochastic process for productivity $\theta_{t}$ and the process that describes distributive shocks $\zeta_{t}$. Moreover, we are especially interested in the parameter that is particularly relevant for the reaction of inequality measures, i.e. the inverse of $\eta$. In the specification for the estimation, we take the results of Ríos-Rull and Santaeulàlia-Llopis (2010), as a starting point and specify a bivariate process of productivity as follows: ${ }^{19}$

$$
\left[\begin{array}{l}
\theta_{t} \\
\zeta_{t}
\end{array}\right]=\left[\begin{array}{cc}
\rho_{\theta} & \rho_{\theta, \zeta} \\
\rho_{\zeta, \theta} & \rho_{\zeta}
\end{array}\right]\left[\begin{array}{l}
\theta_{t-1} \\
\zeta_{t-1}
\end{array}\right]+\left[\begin{array}{l}
\varepsilon_{\theta, t} \\
\varepsilon_{\zeta, t}
\end{array}\right]
$$

where $\rho_{\theta, \zeta}$ and $\rho_{\zeta, \theta}$ denote the off-diagonal elements of the coefficient matrix. In addition, in order to make the estimation of the intertemporal elasticity of substitution more robust, we add observational errors to consumption.

The data series for the estimation for the United States were retrieved from Bureau of Economic Analysis (BEA) and the Bureau of Labor Statistics (BLS). As observables, we use real per capita GDP, the capital share and real private consumption per capita. The data are available for the period 1948Q1:2017Q4. All series are seasonally adjusted, and we apply a one-sided HP filter with $\lambda=1600$ to isolate the cyclical components of the series.

\subsection{Calibration and Priors}

As it is common in the literature, we calibrate a set of parameters to match general properties of the US economy. In particular, we set $\beta$ to 0.988 , this gives an annual steady state interest rate of approximately $4.8 \%$. The depreciation rate $\delta$ is set to be 0.025 , which gives an annual depreciation of $10 \%$, as it is common with quarterly data. Steady state aggregate labor input is calibrated to match the average working time in the United States, we set B to 5.06 and $\gamma=0.5$, this results in average hours worked of 0.23 which translates into 38.6 average working time per week (fulltime equivalent). Regarding the distributional implications of the model, parameters to be determined are $G_{\phi}, G_{a}$ and $G_{y}$. Here calibration targets $G_{a}$ and $G_{\phi}$ for steady state wealth and labor income inequality together with $\alpha$ deliver via (14) a unique value for $G_{y}$. However, as $G_{a}, G_{\phi}$ and $G_{y}$ are tied to each other via (14) not any desired combination of these inequality measures can be reproduced by the model. Whenever we start from the empirical fact that the wealth distribution is

\footnotetext{
${ }^{19}$ This choice reflects the lack of a clear cut understanding of the relationship between both shock processes. We also examine the model dynamics for the case where both shocks are i.i.d. AR(1) processes, as they are commonly employed in the literature. The main conclusions presented below remain unaffected by this choice and the corresponding results are available upon request.
} 


\begin{tabular}{lcll}
\hline \hline Parameter & Value & Description & Target \\
\hline$\beta$ & 0.988 & Subjective discount factor & U.S. annual IR 1965-2016 $\approx 4.8 \%$ \\
$\delta$ & 0.025 & Depreciation rate & \\
$\alpha$ & 0.381 & Steady state capital share & U.S average 1965-2016 $\approx 38 \%$ \\
$\gamma$ & 0.4545 & Inverse Labor supply elasticity & U.S average $\approx 38$ hours/week \\
$G_{a}$ & 0.803 & Steady state Wealth Gini & U.S average 1965-2016 $\approx 80.3 \%$ \\
$G_{y}$ & 0.437 & Steady state Income Gini & U.S average 1965-2016 $\approx 43.7 \%$ \\
\hline \hline
\end{tabular}

Table 3: Calibrated Parameters

the most unequal distribution, it must be the case that $G_{a}>G_{y}>G_{\phi}$. In contrast to this, focusing on coefficients of variation or generalized entropy indices provides more flexibility as it is not necessarily the case that $\sigma_{a}>\sigma_{y}>\sigma_{\phi}$. Focusing on these inequality measures, however, comes at the cost of a loss of clarity as we have a more intuitive understanding of plausible Gini coefficients than of plausible values for coefficients of variation.

The wealth Gini coefficient is calibrated in line with Kuhn et al. (2019) and corresponds to the average Gini coefficient of the wealth distribution reported there, which is has a value of $G_{a}=0.8$. With regards to the Gini coefficients of the income distribution, we use the sample average, obtained from the WIID data, of $G_{y}=0.437$. Finally, we calibrate the steady state capital share in accordance with the sample average and thus set $\alpha=0.381$.

Most prior distributions and priors are chosen as common in the literature. We assume an inverse gamma distribution for the parameters which are bounded to be positive, i.e. $\varepsilon_{\theta, t}$ and $\varepsilon_{\zeta, t}$. We follow Smets and Wouters (2007) and choose a lose prior mean for the innovations of 0.1. With respect to the persistence parameters, $\rho_{\theta}$ and $\rho_{\zeta}$, we assume a beta distribution. We set the prior mean to 0.6 with a standard deviation of 0.2 . Regarding the parameters of the utility function, we assume a normally distributed prior for $\eta$, with a prior mean of 2 and standard deviation of 0.3. In absence of further information on the bivariate process, we use the estimated specification of Ríos-Rull and Santaeulàlia-Llopis (2010) as prior and set the prior mean of $\rho_{\theta, \zeta}$ to 0 and the prior mean of $\rho_{\zeta, \theta}$ to $-0.015 .{ }^{20}$ We assume that the prior distributions are normal and in order to account for parameter uncertainty, we set the standard deviation of both parameters to 0.2. ${ }^{21}$

Table 4 provides an overview of the estimated posterior median values of the parameters. All estimated shocks and parameters are uniquely identified. ${ }^{22} \mathrm{We}$ find that the stochastic processes are estimated to be quite persistent, with a persistence of TFP shocks $\rho_{\theta}$ of 0.97 . The persistence of distributive shocks is estimated to be somewhat lower with a value of 0.95 . Both values are roughly inline with values employed in the literature. With respect to the coefficients of the bivariate process, the results are also reasonably consistent with the results of Ríos-Rull and Santaeulàlia-Llopis (2010). Finally, the estimation yields a value for $\eta$ of 2.4. Thus, in the light

\footnotetext{
${ }^{20}$ As discussed by Ríos-Rull and Santaeulàlia-Llopis (2010), this choice of priors assumes that distributive shocks do not affect TFP, i.e. are purely redistributive and that TFP shocks partially affect the functional income distribution.

${ }^{21}$ As a robustness exercise, we also estimate the parameters of the model with a larger degree of parameter uncertainty, i.e. with a $50 \%$ larger standard deviation of the priors of $\eta, \rho_{\theta, \zeta}$ and $\rho_{\zeta, \theta}$. While this reduces the models ability to identify the relevant parameters, the general results remain largely unaffected.

${ }^{22}$ Identification and sensitivity checks of the model and the estimation can be provided by the authors up on request.
} 
of the preceding discussion, since shocks are found to be persistent and since the intertemporale elasticity of substitution is sufficiently small, we expect inequality measures to react procyclical to TFP shocks on impact.

\begin{tabular}{lcc|cc|cc}
\hline \hline & \multicolumn{3}{c}{ Prior } & \multicolumn{2}{c}{ Posterior } \\
parameter & value & type & mean & std & mode & mean \\
\hline \multicolumn{6}{c}{ Volatility } \\
\hline TFP & $\sigma_{\theta, t}$ & IG & 0.1 & 2 & 0.01 & 0.01 \\
Distr. & $\sigma_{\zeta, t}$ & IG & 0.1 & 2 & 0.02 & 0.02 \\
\hline \multicolumn{6}{c}{ Persistence } \\
\hline TFP & $\rho_{\theta}$ & $\mathrm{B}$ & 0.6 & 0.2 & 0.97 & 0.94 \\
Distr. & $\rho_{\zeta}$ & $\mathrm{B}$ & 0.6 & 0.2 & 0.95 & 0.95 \\
\hline \multicolumn{6}{c}{ Cross-Coefficients } \\
\hline TFP-Distr. & $\rho_{\theta, \zeta}$ & $\mathrm{N}$ & 0.0 & 0.1 & 0.18 & 0.16 \\
Distr.-TFP & $\rho_{\zeta, \theta} \mathrm{N}$ & -0.01 & 0.1 & -0.10 & -0.11 \\
\hline \multicolumn{6}{c}{ Utility function } \\
\hline SE Intertemporal & $\eta \quad \mathrm{N}$ & 2 & 0.3 & 2.38 & 2.41 \\
\hline \hline
\end{tabular}

Table 4: Prior and Posterior distribution of the estimated parameters. The posterior distribution is obtained using the Meteropolis-Hastings algorithm with 2 MCMC chains to generate a sample of 500.000 draws each.

\subsection{Shock contribution and historical comparison}

We analyze the estimated behavior of macroeconomic variables and inequality measures to shocks to total factor productivity and the capital share at the posterior mean. Figure 5 shows the responses of the Gini coefficients of the income (left panel) and wealth distribution (right panel) to a TFP shock ${ }^{23}$ As can be seen, only the initial response of the income Gini coefficient is positive, i.e. behaves procyclical. However, on impact the response is not statistically significant. After around two quarters, income inequality starts to decline and the effect becomes statistically significant. This response is in line with the empirical pattern of cross-correlations between GDP and the Gini coefficient of the income distribution reported in the empirical motivation. Furthermore, the response displays the above mentioned non-monotonic convergence from below after peaking on impact. So overall, while income inequality reacts procyclical on impact, the pattern reverses after some periods and inequality declines. We observe a very similar but less pronounced pattern for wealth inequality.

The distributive shock is modeled as an increase of the capital share and reflects a change in the functional income distribution. The main difference with respect to TFP shocks is that the capital

\footnotetext{
${ }^{23}$ Regarding standard macroeconomic variables we find the well known dynamic patterns for typical business cycle shocks, i.e. output, the real rate, investment and wages go up in response to a TFP shock.
} 

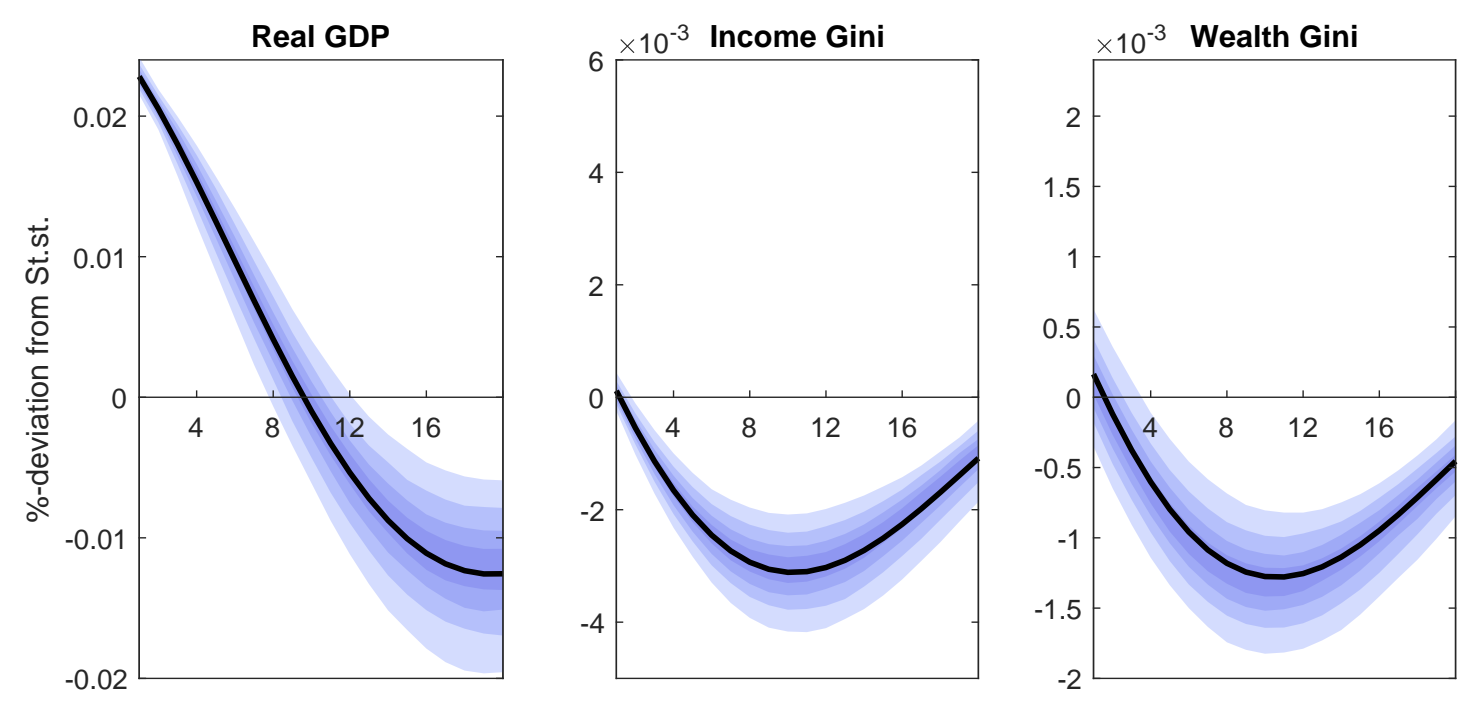

Figure 5: Impulse responses of income and wealth inequality to a positive technology shock at the posterior mean.

share behaves procyclical when the capital share increases endogenously. This is related to the positive growth effects of capital-augmenting technological changes. Figure 6 shows the responses of inequality measures to a distributive shock. Here, clearly a shift towards higher capital intensity in production expands the dispersion of the income and wealth distribution on impact. Only after 10 to 15 quarters, the pattern reverses and inequality declines.
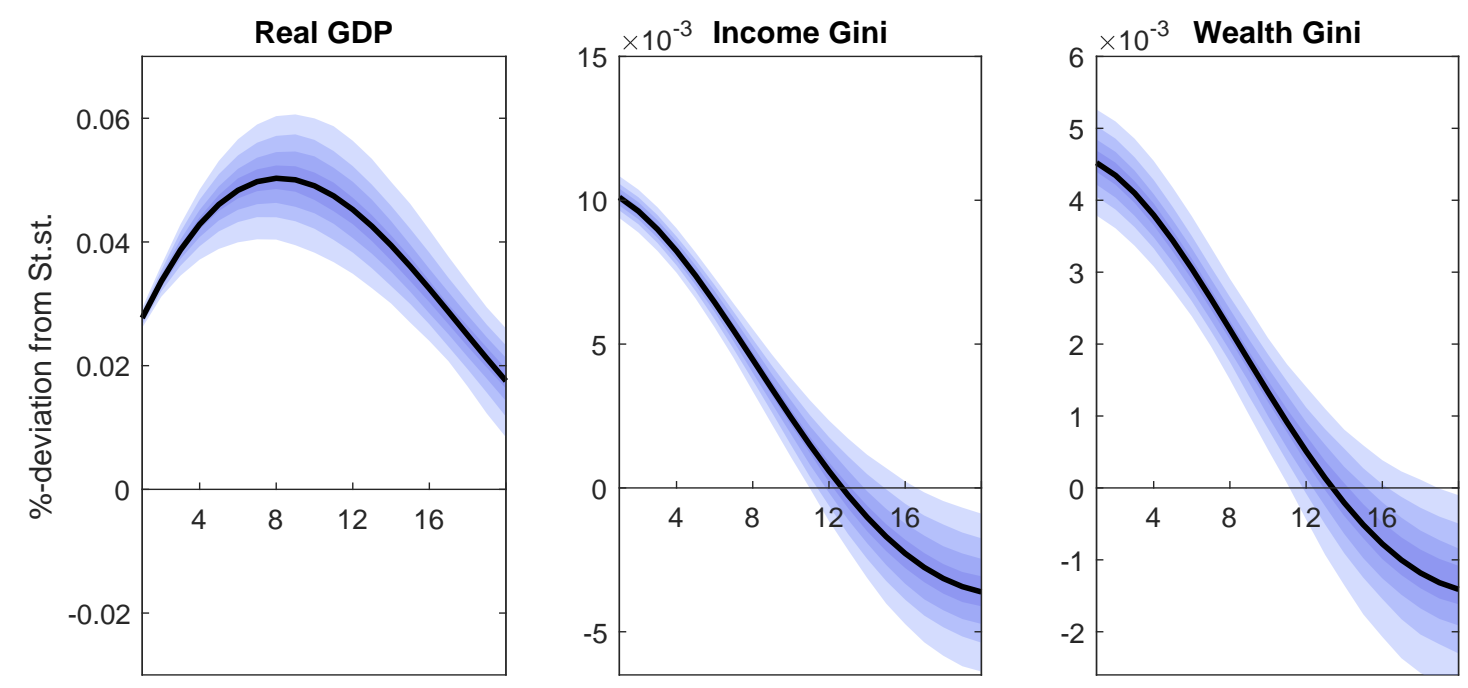

Figure 6: Impulse responses of income and wealth inequality to a positive distributive shock at the posterior mean.

In general we find that income inequality displays a stronger reaction to both types of business 
cycle shocks compared to the reaction of wealth inequality. This suggests that wealth inequality is less susceptible to cyclical fluctuations. ${ }^{24}$ This finding seems intuitive, while changes in wealth inequality are bound to changes in the individual capital stock, which requires an adjustment period, changes in income inequality can materialize directly in response to changes in factor prices. The more pronounced reaction of the Gini coefficient of the income distribution in response to distributive shocks relative to standard TFP shocks can be explained by the direct effect which the distributive shock exerts on the income composition. Intuitively, the redistribution of income towards capital is clearly in favor of wealthier households. Given the assumed functional forms, the distributive shock induces a rise in the real interest rate and an expansion of output. This leads to an increase in investment which translates into a higher capital stock, what eventually leads to an increase in wages. This pattern conforms with the notion of productivity shocks that diffuse slowly into production and primarily benefit capital income, while labor income increases only with a delay after a couple of periods. In contrast, a standard TFP shock increases overall productivity, which induces a broadly proportional increase in labor and capital income, resulting in less dispersion in income.

The results of the historical variance decomposition are summarized in Table 5. Our estimation confirms the results of Young (2004), Ríos-Rull and Santaeulàlia-Llopis (2010) and Lansing (2015) regarding the important role of capital share fluctuations shaping the business cycle. In addition to that, we find that TFP shocks also play a pivotal role in explaining fluctuations in inequality measures. In the case of the United States, about $17 \%$ of the fluctuations in inequality measures can be attributed to TFP shocks. However, according to the model, in the United States, a major share of fluctuations in wealth and income inequality results from distributive shocks. Furthermore, the results of the historical variance decomposition also complement the recent empirical evidence, regarding the long-run relationship between income inequality and changes in GDP growth for the United States as presented by Rubin and Segal (2015). In a panel estimation, they find that GDP changes tend to increase income inequality. According to their results, this finding is particularly driven by the changes in asset income which behaves more volatile than labor income.

\begin{tabular}{llll}
\hline \hline & $G_{y}$ & $G_{a}$ & $y$ \\
\hline TFP & $16.64 \%$ & $15.52 \%$ & $11.07 \%$ \\
Dist. & $83.36 \%$ & $84.48 \%$ & $88.93 \%$ \\
\hline \hline
\end{tabular}

Table 5: Variance decomposition of Gini coefficients of income and wealth.

In a last step, we use the estimated shock decomposition and simulate a historical Gini series, based on observed GDP, consumption and capital share development. In order to compare the model-based series with actual data, we add the HP-filtered trend to the cyclical variations. ${ }^{25}$ However, because quarterly data are not available for the Gini coefficient, we use annual averages

\footnotetext{
${ }^{24}$ This conclusion is also supported by the results of stochastic simulations of the model at the posterior mean. Here we generally find that the standard deviation of the Gini coefficient of the wealth distribution has at most half the size of the standard deviation of the Gini coefficient of the income distribution.

${ }^{25}$ Since the model uses one-sided hp filtered series of all observables, the simulated Gini coefficient is also measured as deviation from steady state.
} 


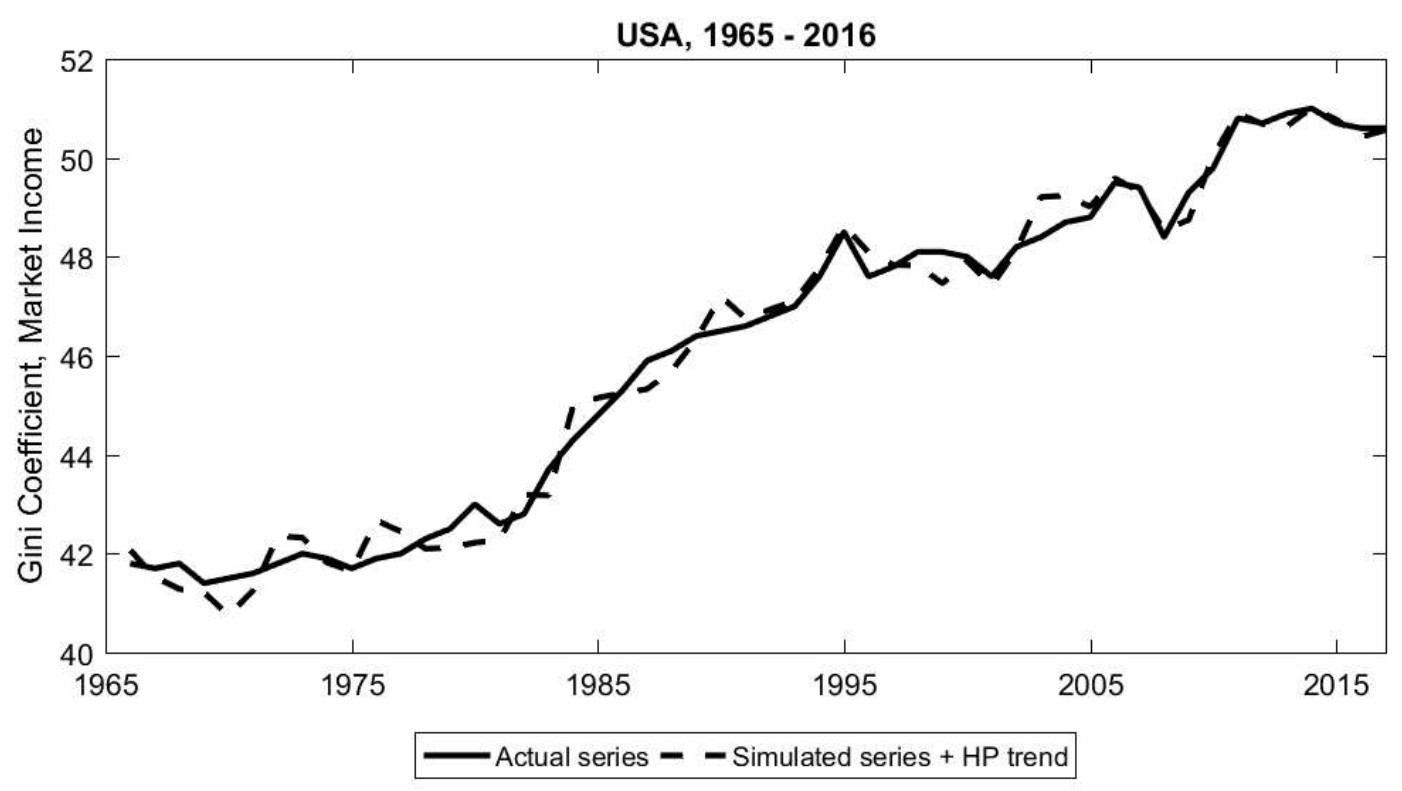

Figure 7: Simulated and actual historical Gini coefficient

of the model-based series and compare actual annual values with quarterly averages. Since we do not include the Gini coefficient as an observable, we consider this to be an interesting exercise to assess the models ability to mimic fluctuations in income inequality.

Figure 7 depicts the actual (solid) and model-based simulated (dashed) historical development of the Gini coefficient for market income. There are three noteworthy aspects. First, major events of increasing or decreasing Gini coefficients can be explained by the model. Second, regarding the US especially in the years 1971-1973 and 1979/80 the model overpredicts the Gini cycle. These time periods are widely regarded as "oil shock" periods. The model here treats the "oil shocks" as negative distributive shock, because GDP and capital share has decreased simultaneously. In the model this would lead to a decrease of income inequality. But instead we observe increasing income inequality during that periods, which could be related to substitutional effects. Firms substitute oil rather through capital (less energy-intensive capital goods) rather than through labor. Introducing energy as third input factor in the production function ${ }^{26}$ could solve that mismatch. Third, we find that the model is able to match the development of income inequality during the great financial crisis in 2007. Here, the model treats the financial crisis as a negative distributive shock, which leads to declining inequality within the model.

\section{Conclusion}

In order to understand the short-run dynamics of inequality, we investigate how the income and wealth distribution evolve along the business cycle. In a panel estimation with annual OECD country data from 1970 to 2016 we find that personal income and wealth inequality measured

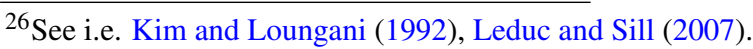


by the Gini coefficient are countercyclical and statistically significant on average. However, by calculating country-specific cyclical correlations of inequality we detect a substantial cross-country heterogeneity: More than half of all OECD countries display a countercyclical relationship between output fluctuations and inequality. Yet, roughly one third of the countries, among others the United States, show an acyclical or even procyclical pattern. In a detailed analysis of the cyclical properties of the income Gini coefficient, we find that in the United States, income inequality is less volatile than output, with a relative standard deviation of about one third.

To understand the driving forces of the income and wealth distribution over the business cycle in more detail, we incorporate distributive shocks in a standard business cycle model, where agents are ex-ante heterogeneous with respect to wealth and ability. We show that this framework allows to derive linearized approximations standard inequality measures such as Gini coefficients. Applying the model to our research question, we show that the cyclicality of these inequality measures depends crucially on the parameters of the model and in particular on the intertemporal elasticity of substitution. Thus, the behaviour of inequality is eventually an empirical question about the size of these two paremters and the relative contribution of TFP as well as distributive shocks.

We match our model to quarterly data for the United States by estimating the shock processes and relevant parameters of the model using Bayesian methods. We find that the intertemporal elasticity of substitution is close to two and that the shock processes display a high degree of persistence. Therefore, both, TFP and distributive shocks generate a procyclical reaction of the income and wealth distribution on impact. However, in response to TFP shocks it declines afterwards, which renders the effect countercyclical in later periods. In case of the distributive shock the dynamics of the income and wealth distribution stays procyclical. This finding matches the empirical cross-correlation pattern between GDP and the Gini coefficient of the income distribution observed in the United States. Furthermore, we find that income inequality reacts more pronounced to business cycle shocks compared to wealth inequality. According to the results of stochastic simulations, the model predicts that wealth inequality is about half as volatile along the business cycle as income inequality.

Finally, we analyze the relative shock contribution according to our posterior specification. Here, we find that the model assigns the major share of fluctuations in inequality measures, roughly $85 \%$ to distributive shocks. Thus, our estimation confirms the important role of fluctuations in factor shares, e.g. due to capital-augmenting technological change, in shaping the business cycle and furthermore highlights its importance for short run inequality dynamics. 


\section{References}

Ahn, SeHyoun, Greg Kaplan, Benjamin Moll, Thomas Winberry, and Christian Wolf, "When Inequality Matters for Macro and Macro Matters for Inequality," in "NBER Macroeconomics Annual 2017, volume 32” NBER Chapters, National Bureau of Economic Research, Inc, 2017, pp. $1-75$.

Aiyagari, Rao S., "Uninsured Idiosyncratic Risk and Aggregate Saving," The Quarterly Journal of Economics, 1994, 109 (3), $659-684$.

Alvaredo, Facundo, Lucas Chancel, Thomas Piketty, Emmanuel Saez, and Gabriel Zucman, “Global Inequality Dynamics: New Findings from WID.world," American Economic Review, May 2017, 107 (5), 404-09.

Atkinson, A. B., "Factor shares: the principal problem of political economy?," Oxford Review of Economic Policy, 2009, 25 (1), 3 - 16.

Barro, Robert J, "Inequality and Growth in a Panel of Countries," Journal of Economic Growth, 2000, 5 (1), 5-32.

Bayer, Christian and Ralph Luetticke, "Solving heterogeneous agent models in discrete time with many idiosyncratic states by perturbation methods," CEPR Discussion Papers 13071, C.E.P.R. Discussion Papers July 2018.

_ and _ , "Shocks, Frictions, and Inequality in US Business Cycles," Technical Report 2019.

Cantore, Cristiano, Filippo Ferroni, and Miguel A. Leon-Ledesma, "The Missing Link: Monetary policy and the labor share," Discussion Papers 1829, Centre for Macroeconomics (CFM) November 2018.

Caselli, Francesco and Jaume Ventura, "A Representative Consumer Theory of Distribution," American Economic Review, 2000, 90 (4), 909 - 926.

Challe, Edouard, Julien Matheron, Xavier Ragot, and Juan F. Rubio-Ramirez, "Precautionary saving and aggregate demand," Quantitative Economics, 2017, 8 (2), 435-478.

Chatterjee, Satyajit, "Transitional dynamics and the distribution of wealth in a neoclassical growth model," Journal of Public Economics, 1994, 54 (1), 97 - 119.

Debortoli, Davide and Jordi Galí, "Monetary policy with heterogeneous agents: Insights from TANK models," Economics Working Papers 1686, Department of Economics and Business, Universitat Pompeu Fabra September 2017.

Dimelis, Sophia and Alexandra Livada, "Inequality and business cycles in the U.S. and European Union countries," International Advances in Economic Research, Aug 1999, 5 (3), 321-338.

Feenstra, Robert C., Robert Inklaar, and Marcel P. Timmer, "The Next Generation of the Penn World Table," American Economic Review, 2015, 105 (10), 3150 - 3182. 
Galí, Jordi, J. David López-Salido, and Javier Vallés, "Understanding the Effects of Government Spending on Consumption," Journal of the European Economic Association, 2007, 5 (1), 227 270 .

Growiec, Jakub, Peter McAdam, and Jakub Mućk, "Endogenous labor share cycles: Theory and evidence," Journal of Economic Dynamics and Control, 2018, 87 (C), 74-93.

Iacoviello, Matteo, "House Prices, Borrowing Constraints, and Monetary Policy in the Business Cycle," American Economic Review, 2005, 95 (3), 739-764.

Kaplan, Greg and Giovanni L. Violante, "Microeconomic Heterogeneity and Macroeconomic Shocks," Journal of Economic Perspectives, 2018, 32 (3), 167-194.

_ , Benjamin Moll, and Giovanni L. Violante, "Monetary Policy According to HANK," American Economic Review, 2018, 108 (3), 697-743.

Kim, In-Moo and Prakash Loungani, "The role of energy in business cycle models," Journal of Monetary Economics, 1992, 29 (2), 173 - 189.

Kuhn, Moritz, Moritz Schularick, and Ulrike Steins, "Wealth and Income Inequality in America, 1949-2016," Journal of Political Economy, 2019, forthcoming.

Lansing, Kevin J., "Asset Pricing with Concentrated Ownership of Capital and Distribution Shocks," American Economic Journal: Macroeconomics, 2015, 7 (4), 67 - 103.

Leduc, Sylvian and Keith Sill, "Monetary policy, oil shocks, and TFP: Accountinf for the decline in US volatility," Review of Economic Dynamics, 2007, 10 (4), 595 - 614.

List, John A and Craig A Gallet, "The Kuznets Curve: What Happens after the Inverted-U?," Review of Development Economics, 1999, 3 (2), 200-206.

Maliar, Lilia and Serguei Maliar, "Heterogeneity in capital and skills in a neoclassical stochastic growth model," Journal of Economic Dynamics and Control, 2001, 25 (9), 1367 - 1397.

_, _, and Juan Mora, "Income and Wealth Distributions Along the Business Cycle: Implications from the Neoclassical Growth Model," Topics in Macroeconomics, 2005, 5 (1).

Mangin, Sephorah and Petr Sedláček, "Unemployment and the labor share," Journal of Monetary Economics, 2018, 94 (C), 41-59.

Pothier, David and Damien Puy, "Demand Composition and Income Distribution," IMF Working Papers 14/224, International Monetary Fund 2014.

Ragot, Xavier and Francois Le Grand, "Optimal Fiscal Policy with Heterogeneous Agents and Aggregate Shocks,” Technical Report 2017.

Ríos-Rull, José-Víctor and Raül Santaeulàlia-Llopis, "Redistributive shocks and productivity shocks," Journal of Monetary Economics, 2010, 57 (8), 931 - 948. 
Rubin, Amir and Dan Segal, "The effects of economic growth on income inequality in the US," Journal of Macroeconomics, 2015, 45, 258 - 273.

Smets, Frank and Rafael Wouters, "Shocks and Frictions in US Business Cycles: A Bayesian DSGE Approach,” American Economic Review, 2007, 97 (3), 586-606.

Young, Andrew, "Labor's Share Fluctuations, Biased Technical Change, and the Business Cycle," Review of Economic Dynamics, 2004, 7 (4), 916-931.

\section{Appendix}

\section{Appendix A: Data description}

\section{Panel estimation (annual data)}

Real GDP: Expenditure-side real GDP at chained PPPs (in mil. 2011US\$) (rgdpe), Penn world database.

Population: Population (in millions) (pop), Penn World Database 9.0.

Income Inequality: Net Gini Coefficient of disposable income, SWIIID Database 7.1.

Income Inequality: Gross Gini Coefficient before redistribution measure, UN WIDER Database 9.0.

Labor share: Share of labour compensation in GDP at current national prices (labsh), Penn World Database 9.0.

\section{Bayesian estimation (quarterly data) for the United States}

Output: Real Gross Domestic Product, BEA, NIPA table 1.1.6, line 1, billions of chained 2012 dollars seasonally adjusted at annual rate.

Consumption: Personal Consumption Expenditure on Nondurable Goods, BEA, NIPA table 1.1.5, line 5, billions of dollars, seasonally adjusted at annual rate and Personal Consumption Expenditure on Services, BEA NIPA table 1.1.5, line 6, billions of dollars, seasonally adjusted at annual rate. Labor share: BLS estimates of the nonfarm business sector labor share, Data reflects press release of February 6,2019.

\section{Appendix B: Derivation of Inequality measures}

\section{Appendix B.1: Linearization of the variance of the wealth and income distribution}

This appendix demonstrates how to derive a linearized representation of the variances of the wealth and income distribution. The variance of the wealth distribution is given by:

$$
\sigma_{a, t+1}^{2}=\left(p_{0} q_{t}\right)^{2} \sigma_{\mathfrak{a}}^{2}+\left(1-p_{0} q_{t}\right)^{2} \sigma_{\phi}^{2}+2\left(p_{0} q_{t}\right)\left(1-p_{0} q_{t}\right) \sigma_{\mathfrak{a}, \phi}^{2}
$$

In the stochastic steady state we have $\sigma_{a}^{2}=\left(p_{0} q\right)^{2} \sigma_{\mathfrak{a}}^{2}+\left(1-p_{0} q\right)^{2} \sigma_{\phi}^{2}+2\left(p_{0} q\right)\left(1-p_{0} q\right) \sigma_{\mathfrak{a}, \phi}^{2}$, where $q$ denotes the unconditional mean of $q_{t}$. A first order approximation of $\sigma_{a, t+1}^{2}$ around $q$ then 
gives:

$$
\sigma_{a, t+1}^{2} \approx \sigma_{a}^{2}+2 q_{t}\left[\left(p_{0} q\right)^{2} \sigma_{\mathfrak{a}}^{2}-\left(1-p_{0} q\right) p_{0} q \sigma_{\phi}^{2}+\left(p_{0} q-2\left(p_{0} q\right)^{2}\right) \sigma_{\mathfrak{a}, \phi}^{2}\right]
$$

Using the above stated expression for $\sigma_{a}^{2}$, this becomes:

$$
\sigma_{a, t+1}^{2} \approx \sigma_{a}^{2}+2 \hat{q}_{t}\left[\sigma_{a}^{2}-\left(1-p_{0} q\right) \sigma_{\phi}^{2}-p_{0} q \sigma_{\mathfrak{a}, \phi}^{2}\right]
$$

Because $\sigma_{a, \phi}^{2}=p_{0} q \sigma_{\mathfrak{a}, \phi}^{2}+\left(1-p_{0} q\right) \sigma_{\phi}^{2}$, we finally end up with:

$$
\begin{aligned}
\sigma_{a, t+1}^{2} \approx & \sigma_{a}^{2}+2 \hat{q}_{t}\left[\sigma_{a}^{2}-\sigma_{a, \phi}^{2}\right] \\
& =\sigma_{a}^{2}+2 \hat{q}_{t} \sigma_{a}^{2}\left(1-\rho_{a, \phi} \frac{\sigma_{\phi}}{\sigma_{a}}\right) \\
\Leftrightarrow \quad \widehat{\sigma}_{a, t+1}^{2} & \approx 2 \hat{q}_{t}\left(1-\rho_{a, \phi} \frac{\sigma_{\phi}}{\sigma_{a}}\right)
\end{aligned}
$$

With respect to the income distribution we have $y(i)_{t}=\left(\alpha_{t} p_{0} q_{t-1}\right) \mathfrak{a}(i)+\left(1-\alpha_{t} p_{0} q_{t-1}\right) \phi(i)$. Thus, the variance of the income distribution is given by:

$$
\sigma_{y, t}^{2}=\left(\alpha_{t} p_{0} q_{t-1}\right)^{2} \sigma_{\mathfrak{a}}^{2}+\left(1-\alpha_{t} p_{0} q_{t-1}\right)^{2} \sigma_{\phi}^{2}+2\left(\alpha_{t} p_{0} q_{t-1}\right)\left(1-\alpha_{t} p_{0} q_{t-1}\right) \sigma_{\mathfrak{a}, \phi}^{2}
$$

In the stochastic steady state we have $\sigma_{y}^{2}=\left(\alpha p_{0} q\right)^{2} \sigma_{\mathfrak{a}}^{2}+\left(1-\alpha p_{0} q\right)^{2} \sigma_{\phi}^{2}+2\left(\alpha p_{0} q\right)(1-$ $\left.\alpha p_{0} q\right) \sigma_{\mathfrak{a}, \phi}^{2}$ and a linearization of $\sigma_{y, t}^{2}$ around $q$ and $\alpha$ gives:

$$
\begin{aligned}
\sigma_{y, t}^{2} \approx \sigma_{y}^{2} & +2 \hat{q}_{t-1}\left[\left(\alpha p_{0} q\right)^{2} \sigma_{\mathfrak{a}}^{2}-\left(1-\alpha p_{0} q\right) \alpha p_{0} q \sigma_{\phi}^{2}+\left(\alpha p_{0} q-2\left(\alpha p_{0} q\right)^{2}\right) \sigma_{\mathfrak{a}, \phi}^{2}\right] \\
& +2 \hat{\alpha}_{t}\left[\left(\alpha p_{0} q\right)^{2} \sigma_{\mathfrak{a}}^{2}-\left(1-\alpha p_{0} q\right) \alpha p_{0} q \sigma_{\phi}^{2}+\left(\alpha p_{0} q-2\left(\alpha p_{0} q\right)^{2}\right) \sigma_{\mathfrak{a}, \phi}^{2}\right]
\end{aligned}
$$

Using the expression for $\sigma_{y}^{2}$ from above, this becomes:

$$
\sigma_{y, t}^{2} \approx \sigma_{y}^{2}+2\left(\hat{q}_{t-1}+\hat{\alpha}_{t}\right)\left[\sigma_{y}^{2}-\left(1-\alpha p_{0} q\right) \sigma_{\phi}^{2}-\left(\alpha p_{0} q\right) \sigma_{\mathfrak{a}, \phi}^{2}\right]
$$

Because $\sigma_{y, \phi}^{2}=\alpha p_{0} q \sigma_{\mathfrak{a}, \phi}^{2}+\left(1-\alpha p_{0} q\right) \sigma_{\phi}^{2}$, this equation is equivalent to:

$$
\begin{aligned}
& \sigma_{y, t}^{2} \approx \sigma_{y}^{2}+2\left(\hat{q}_{t-1}+\hat{\alpha}_{t}\right)\left[\sigma_{y}^{2}-\sigma_{y, \phi}^{2}\right] \\
&=\sigma_{y}^{2}+2\left(\hat{q}_{t-1}+\hat{\alpha}_{t}\right) \sigma_{y, *}^{2}\left[1-\rho_{y, \phi} \frac{\sigma_{\phi}}{\sigma_{y}}\right] \\
& \Leftrightarrow \quad{\widehat{\sigma^{2}}}_{y, t} \approx 2\left(\hat{q}_{t-1}+\hat{\alpha}_{t}\right)\left[1-\rho_{y, \phi} \frac{\sigma_{\phi}}{\sigma_{y}}\right]
\end{aligned}
$$

\section{Appendix C: Generalized entropy measures}

This appendix demonstrates how to derive the generalized entropy index of the wealth distribution. Since we have $\int_{0}^{1} a(i) d i=1$ the GE-index for the wealth distribution in period $t$ is given by $(a(i)$ 
denotes the steady-state value of $\left.a(i)_{t}\right)$ :

$$
G E(\tau)_{a, t+1}=\frac{1}{\tau(\tau-1)} \int_{0}^{1} a(i)_{t+1}^{\tau}-1 d i
$$

Now, $a(i)_{t+1}=\left[a(i)_{0}-\phi(i)\right] p_{0} q_{t}+\phi(i)$. Thus a first order approximation of $G E(\tau)_{a, t+1}$ around $q$ gives:

$$
G E(\tau)_{a, t+1}-G E(\tau)_{a}=\frac{\hat{q}_{t}}{\tau-1} \int_{0}^{1} a(i)^{\tau-1}[a(i)-\phi(i)] d i
$$

If the expression under the integral is approximated by a second order Taylor polynomial around $a(i)=1$ and $\phi(i)=1$, we get:

$$
\begin{aligned}
a(i)^{\tau-1}(a(i)-\phi(i)) \approx & {[a(i)-1]-[\phi(i)-1] } \\
& +(\tau-1)\left([a(i)-1]^{2}-[a(i)-1][\phi(i)-1]\right)
\end{aligned}
$$

Thus the integral can be approximated as

$$
\int_{0}^{1} a(i)^{\tau-1}[a(i)-\phi(i)] d i \approx(\tau-1) \sigma_{a}^{2}\left[1-\rho_{a, \phi} \frac{\sigma_{\phi}}{\sigma_{a}}\right]
$$

Finally, a second order approximation of $G E(\tau)_{a}$ around $a(i)=1$ and $\phi(i)=1$ gives:

$$
G E(\tau)_{a} \approx \frac{1}{2} \sigma_{a}^{2}
$$

Substituting this expression and the approximated expression for the integral into (19) then gives:

$$
\widehat{G E}(\tau)_{a, t+1}=2 \hat{q}_{t}\left(1-\rho_{a, \phi} \frac{\sigma_{\phi}}{\sigma_{a}}\right)
$$

Proceeding in a similar fashion it is possible to derive a measure for the income distribution. 